\title{
Análise do desempenho de adensamento da massa refratária de sílica usada em fornos de indução
}

\section{(Analysis of the densification performance of silica refractory mass used in induction furnaces)}

\author{
M.B.A. Bruno ${ }^{1 *}$, C.Pacheco ${ }^{I}$, G. Gomes ${ }^{I}$, M. V. Folgueras ${ }^{I}$ \\ ${ }^{1}$ Universidade do Estado de Santa Catarina, PGCEM, R. Paulo Malschitzki, s/n, 89290-710, Joinville, SC, Brasil
}

\begin{abstract}
Resumo
As indústrias de fundição de ferro fundido usam em seu processo grande quantidade de sucata zincada, o que tem contribuído para a redução da campanha do revestimento refratário de fornos de indução a cadinho já que o vapor de zinco formado no aquecimento migra para o centro do refratário, condensando em regiões externas do forno, próximo à bobina refrigerada, gerando curto circuito entre as espiras. O revestimento refratário usado é uma massa seca à base de sílica conformada por vibração. Foram comparadas quatro massas de sílica, com base na morfologia e distribuição granulométrica, para explicar o comportamento de adensamento. Foram avaliadas também a porosidade aberta, absorção de água e retração linear das massas sinterizadas. A massa que apresentou maior densidade vibrada e sinterizada foi indicada para minimizar penetração de vapores e escórias. A única restrição seria a maior influência do processo de compactação sobre o adensamento deste material.
\end{abstract}

Palavras-chave: sílica, massa refratária, forno de indução.

Abstract

The cast iron foundry industries use a large amount of scrap zinc in their process which has contributed to the reduction of the refractory campaign on induction furnaces by the generation of zinc vapor that migrates to the center of the refractory lining, condensing in outer regions of the furnace which generates a short circuit between the turns. The refractory lining used in the furnaces is a dry mass based on silica conformed by vibration. Four silica refractories were compared, based on the morphology and particle size distribution to explain the densification behavior. Open porosity, water absorption and linear retraction of the sintered mass were also evaluated. The mass that presented a higher vibrated and sintered density would be indicated to minimize the penetration of vapors and slags. The only restriction would be the greater influence of the compaction process of this material. Keywords: silica, refractory mass, induction furnace.

\section{INTRODUÇÃO}

Nos processos de fundição os fornos são revestidos por materiais refratários selecionados com base no tipo de material a ser fundido. Estes refratários têm como função básica a contenção do metal líquido e o isolamento térmico para garantir a estabilidade da temperatura durante o processo [1]. O bom desempenho dos revestimentos empregados é refletido na qualidade do produto metálico produzido, no melhor controle da temperatura interna e externa do forno, na maior vida útil dos fornos, na redução dos custos de manutenção corretiva e na diminuição do número de acidentes relacionados com as falhas do refratário. Em um forno de indução, a camada de material refratário separa a parede interna do forno da bobina de cobre, por onde passa uma corrente elétrica e é gerado um campo magnético. A bobina de cobre é mantida livre de superaquecimento pela ação da água de resfriamento que circula em seu interior

*maressabruno@gmail.com

(D) https://orcid.org/0000-0002-7198-2502
[2]. Este resfriamento garante também a menor temperatura na superfície externa da camada refratária e define o gradiente de temperatura entre a superfície interna e externa do refratário [2]. A espessura da camada refratária deve ser suficientemente fina para garantir a melhor eficiência de fusão, entretanto deve ter espessura adequada para garantir a proteção total da bobina prevenindo penetração do metal fundido, agentes químicos e choques mecânicos [2]. Esta espessura também pode ser definida em função das características de adensamento do refratário utilizado. Os refratários empregados em fornos de indução foram inicialmente tijolos refratários ou massas refratárias úmidas. Posteriormente foram substituídos por massa refratária seca, com adição de óxido de boro como agente de sinterização. $\mathrm{O}$ óxido de boro é adicionado em teores que variam em função da temperatura em que é utilizado, sendo que adições maiores são empregadas para temperaturas de trabalho menor [3].

A formação da camada refratária sobre uma fôrma metálica de aço foi inicialmente produzida por adensamento manual onde se utilizavam grandes garfos como ferramenta para acomodar o material particulado. Atualmente utilizam- 
se equipamentos para realizar o adensamento por vibração. No processo de compactação devem ser considerados procedimentos que evitem a segregação de partículas de diferentes dimensões [1]. De forma geral, a compactação inadequada do refratário pode resultar na formação de vazios ou áreas de baixa densidade, criando pontos frágeis que podem ser atacados pelo metal fundido [2]. O melhor desempenho do cadinho é medido pelo número de corridas realizadas, sendo que o revestimento refratário, após as primeiras corridas, é formado por três diferentes camadas, ditas camada vidrada, camada semissinterizada e camada solta. A camada vidrada é a que está em contato com o metal, enquanto a camada solta é a que está em contato com a bobina [1]. É importante destacar que em geral a primeira corrida do forno, onde ocorre o primeiro processo de sinterização do refratário, acontece com o forno carregado com metal e nesta condição é facilitada a penetração de materiais volatilizados através da porosidade existente no refratário não sinterizado. As características de cada uma destas camadas são influenciadas pela eficiência de adensamento, que por sua vez depende da dispersão do tamanho de partículas da massa refratária seca. Maximizar o adensamento pelo controle da distribuição de tamanho de partícula traz como benefício a redução da porosidade e aumento da resistência à corrosão do refratário durante as corridas, entretanto o aumento da densificação pode atuar de forma negativa em propriedades como resistência ao choque térmico, em função do efeito de expansão do material como resultado do aquecimento e de transformações de fase. No caso específico dos refratários de sílica devem ser consideradas as transformações polimórficas da sílica que ocorrem durante o aquecimento e resfriamento do refratário.

A distribuição de tamanho de partículas, para garantir a máxima densificação, pode ser alcançada por meio do estudo de modelos de empacotamento, que levam em consideração a distribuição do tamanho de partículas. Entre os modelos mais utilizados para o estudo de adensamento em materiais cerâmicos particulados estão os modelos de Alfred e Andreassen [4-6]. A utilização destes modelos deve ser associada à avaliação de morfologia de partículas e densidade das mesmas [4]. A eficiência de adensamento pode ser avaliada através da determinação de parâmetros como densidade aparente, densidade de socagem (densidade vibrada) e densidade solta. Estas medidas permitem avaliar o grau de adensamento e a correlação entre os modelos teóricos propostos e o desempenho do material. A vida útil do refratário depende também das características do metal a ser fundido. Cada vez mais as fundições necessitam realizar alterações na composição da carga com base nas matériasprimas disponíveis no mercado. O melhor material a ser empregado como matéria-prima para a produção de ferros fundidos é o ferro gusa por apresentar maior densidade e homogeneidade, entretanto o uso de sucata é uma realidade. $\mathrm{Na}$ produção de ferros fundidos, em geral, são empregadas sucatas de aço. Estas sucatas podem apresentar-se parcialmente oxidadas ou possuírem superfícies pintadas ou zincadas, o que pode resultar em perda de qualidade para o metal produzido e reduzir o desempenho do revestimento refratário [7]. Em especial a presença de metais de baixa temperatura de fusão e vaporização pode resultar na degradação do refratário pela ação dos voláteis gerados que penetram na porosidade do refratário. A proposta aqui apresentada foi a de avaliar o desempenho de adensamento de diferentes massas refratárias secas empregadas em fornos de indução e correlacionar estes resultados com as curvas de distribuição de tamanho de partículas e análise morfológica dos materiais particulados que formam o refratário. As curvas de distribuição granulométrica obtidas foram avaliadas com base no modelo de Andreassen. Após o adensamento, foram avaliadas as características físicas dos materiais sinterizados a $1400{ }^{\circ} \mathrm{C}$ : densidade, porosidade aberta, absorção de água e retração linear.

\section{MATERIAIS E MÉTODOS}

Foram selecionados quatro diferentes materiais refratários utilizados rotineiramente em indústrias de fundição de ferro fundido. As informações comerciais destes materiais estão apresentadas na Tabela I. Os materiais foram recebidos e armazenados em ambientes fechados. Todos os materiais foram apresentados na forma de massa refratária seca, produzida pela combinação de sílica e aditivos. $\mathrm{O}$ teor de óxido de boro utilizado variou entre $0,7 \%$ e $0,9 \%$ em massa. Os materiais identificados como R1, $\mathrm{R} 2, \mathrm{R} 3$ e R4 foram caracterizados quanto à sua densidade picnométrica, densidade solta, densidade vibrada, densidade sinterizada, distribuição granulométrica, difração de raios $\mathrm{X}$, morfologia de partículas, porosidade aberta, absorção de água e retração linear. Todos os ensaios foram realizados em laboratório seguindo procedimentos padronizados. As curvas de distribuição granulométrica foram comparadas com as curvas obtidas com base no modelo de Andreassen.

Tabela I - Informações comerciais das quatro massas refratárias secas utilizadas.

[Table I - Commercial information of the four dry refractory used.]

\begin{tabular}{|c|c|c|c|c|c|c|}
\hline \multirow{2}{*}{ Refratário } & \multicolumn{4}{|c|}{ Composição (\% em massa) } & \multirow{2}{*}{$\begin{array}{l}\text { Tamanho máximo } \\
\text { de grão }(\mathrm{mm})\end{array}$} & \multirow{2}{*}{$\begin{array}{c}\text { Densidade de } \\
\text { empacotamento }\left(\mathrm{g} / \mathrm{cm}^{3}\right)\end{array}$} \\
\hline & $\mathrm{SiO}_{2}$ & $\mathrm{~B}_{2} \mathrm{O}_{3}$ & $\mathrm{Al}_{2} \mathrm{O}_{3}$ & $\mathrm{Fe}_{2} \mathrm{O}_{3}$ & & \\
\hline $\mathrm{R} 1$ & 97,5 & 0,7 a 0,9 & $<1,0$ & - & 9,5 & 2,15 \\
\hline $\mathrm{R} 2$ & 98,0 & 0,8 & - & - & 7,0 & 2,20 \\
\hline R3 & 99,0 & 0,8 & - & - & 6,0 & 2,15 \\
\hline R4 & 99,0 & 0,8 & - & $0,1 \%$ & 12,0 & 2,21 \\
\hline
\end{tabular}


Os resultados de adensamento foram analisados com base na análise das curvas de distribuição granulométrica e morfologia dos materiais particulados.

Densidade solta $\left(D_{S}\right)$ : corresponde à densidade de empacotamento do material resultante apenas da acomodação das partículas em um volume sem a realização de nenhuma ação que possa favorecer a densificação. A densidade alcançada é o resultado da acomodação das partículas. Para este ensaio foi utilizado um recipiente metálico cilíndrico com volume interno de $1000 \mathrm{~cm}^{3}$. Também foi utilizada uma peneira com abertura suficiente para passar todo o material. Foi mantida fixa a distância em que o material foi despejado. A densidade solta foi determinada com base na Eq. A, onde $\mathrm{V}_{1}$ é o volume interno do molde e $\mathrm{M}_{1}$ é a massa sólida necessária para preencher todo o molde:

$$
\mathrm{D}_{\mathrm{S}}=\frac{\mathrm{M}_{1}}{\mathrm{~V}_{1}}
$$

Densidade vibrada $\left(D_{V}\right)$ : corresponde à densidade de empacotamento do material quando submetido à ação de pressão e vibração. Para este ensaio foram pesados $300 \mathrm{~g}$ de massa refratária e transferidos para uma proveta com diâmetro de 26,6 mm. A cada adição de $30 \mathrm{~g}$ de material na proveta, o material foi adensado com o uso de uma haste tipo garfo durante $2 \mathrm{~min}$. Após o preenchimento da proveta com todo o material, o conjunto foi submetido à vibração em mesa vibratória de laboratório por $5 \mathrm{~min}$. A densidade vibrada foi determinada com base na Eq. B, onde $\mathrm{M}_{2}$ é a massa de sólido empregada no ensaio, $\mathrm{R}$ é o diâmetro interno da proveta e $\mathrm{L}$ é a altura da coluna preenchida por sólido na proveta:

$$
\mathrm{D}_{\mathrm{v}}=\frac{\mathrm{M}_{2}}{\mathrm{~L} \cdot \pi \cdot \mathrm{R}^{2}}
$$

Densidade picnométrica $\left(D_{p}\right)$ : corresponde à densidade do material sólido que compõe a massa refratária. O material foi previamente moído em panela trituradora com dois anéis de aço por $2 \mathrm{~min}$, garantindo $100 \%$ de material passante em peneira de abertura de $0,25 \mathrm{~mm}$. Para a determinação da densidade picnométrica utilizou-se uma amostra de $9 \mathrm{~g}$ de massa refratária moída e um picnômetro a gás (AccuPyc 1340, Micromeritics). O resultado apresentado corresponde à média de 10 medidas. Os valores de densidade picnométrica foram utilizados para a determinação da densidade relativa $\left(\mathrm{D}_{\mathrm{R}}\right)$.

Densidade sinterizada $\left(D_{S}\right)$ e retração linear $(R L)$ : as massas refratárias foram preparadas em misturador planetário, adicionando $2 \%$ em massa de dextrina e $5 \%$ em massa de água durante $5 \mathrm{~min}$ para atingir homogeneidade. Em seguida, para cada mistura, foram confeccionados 3 corpos de prova cilíndricos de 50x50 mm. Os componentes foram conformados por garfeamento seguido de compactação mecânica uniaxial, sendo esta de 10 percussões com força de $1 \mathrm{MPa}$. Os corpos de prova foram submetidos à secagem em estufa por $24 \mathrm{~h}$ a $100{ }^{\circ} \mathrm{C}$. Após secagem, foram obtidos os valores de massa seca $\left(\mathrm{P}_{\mathrm{s}}\right)$ e altura do corpo de prova $\left(\mathrm{L}_{\mathrm{s}}\right)$. A sinterização foi realizada em forno mufla por aquecimento a $1400{ }^{\circ} \mathrm{C}$ por $30 \mathrm{~min}$. Foi utilizada taxa de aquecimento de $1,5^{\circ} \mathrm{C} / \mathrm{min}$. A temperatura de $1400{ }^{\circ} \mathrm{C}$ foi selecionada por ser suficiente para identificar a redução da porosidade nos estágios iniciais de aquecimento. Esta porosidade inicial é responsável pela penetração do vapor de zinco no primeiro ciclo de aquecimento no forno de indução a cadinho. A densidade sinterizada foi obtida a partir das dimensões dos corpos de prova, altura $\left(\mathrm{L}_{\mathrm{q}}\right) \mathrm{e}$ diâmetro, além da massa. A retração linear de queima foi determinada utilizando a Eq. C:

$$
\mathrm{RL}=\frac{\mathrm{L}_{\mathrm{S}}-\mathrm{L}_{\mathrm{q}}}{\mathrm{L}_{\mathrm{S}}}
$$

Porosidade aparente (PA) e absorção de água (AA): os corpos de prova sinterizados foram imersos em água fervente por $60 \mathrm{~min}$, deixando-os resfriar submersos. Com a água e os corpos de prova à temperatura ambiente, os corpos foram retirados, secos em pano úmido e pesados para determinação da massa úmida $\left(\mathrm{P}_{\mathrm{u}}\right)$. Calculou-se a absorção de água a partir da Eq. D. Para o cálculo da porosidade aparente, utilizou-se o princípio de Arquimedes (Eq. E), onde foi obtida a massa imersa $\left(\mathrm{P}_{\mathrm{i}}\right)$ :

$$
\begin{aligned}
& \mathrm{AA}=\frac{\mathrm{P}_{\mathrm{u}}-\mathrm{P}_{\mathrm{s}}}{\mathrm{P}_{\mathrm{s}}} \\
& \mathrm{PA}=\frac{\mathrm{P}_{\mathrm{u}}-\mathrm{P}_{\mathrm{s}}}{\mathrm{P}_{\mathrm{u}}-\mathrm{P}_{\mathrm{i}}}
\end{aligned}
$$

Distribuição granulométrica: a curva de distribuição granulométrica das massas refratárias foi construída com dados obtidos por separação granulométrica em peneiras. Foram empregadas peneiras com abertura entre 12 e 0,038 $\mathrm{mm}$. O ensaio foi realizado utilizando $50 \mathrm{~g}$ de massa refratária e processo de peneiramento realizado por $15 \mathrm{~min}$ em sistema automático de peneiramento. Foi determinada a massa retida em cada uma das peneiras.

Morfologia das partículas: para a análise morfológica dos materiais particulados os refratários foram divididos em três frações denominadas fina, média e grossa. $\mathrm{O}$ material com partículas de granulometria inferior a $0,106 \mathrm{~mm}$ foi denominado fração fina. O material com partículas de granulometria superior a $2,00 \mathrm{~mm}$ foi denominado fração grosseira enquanto o material restante foi classificado como fração média. A observação do material foi realizada por microscopia óptica.

\section{RESULTADOS E DISCUSSÃO}

Os quatro materiais considerados para análise foram fornecidos com a denominação de massa refratária seca de sílica. Estes materiais foram produzidos utilizando quartzitos naturais ou quartzo de rocha como matériasprimas predominantes. Estes materiais possuíram elevado teor de sílica, podendo ter como elementos secundários alumínio e ferro, oriundos de óxidos ou minerais [8]. A estes materiais foram adicionadas pequenas quantidades de óxido de boro, ou ácido bórico, que tem a função de favorecer a sinterização do material durante o aquecimento. 
$\mathrm{O}$ ácido bórico $\left(\mathrm{H}_{3} \mathrm{BO}_{3}\right)$ é um pó branco com ponto de fusão de $169^{\circ} \mathrm{C}$ e densidade de $1,51 \mathrm{~g} / \mathrm{cm}^{3}$. O aquecimento deste material na presença de umidade leva à formação de óxido de boro [9]. Este óxido por sua vez apresenta temperatura de fusão $450{ }^{\circ} \mathrm{C}$. Tanto no quartzito como no quartzo de rocha predomina a presença da sílica na forma de quartzo, sendo que no quartzito é comum a presença de pequenas frações de sílica vítrea, o que pode aumentar a reatividade do material. O quartzo, que apresenta densidade de 2,65 $\mathrm{g} / \mathrm{cm}^{3}$, pode sofrer transformações polimórficas durante $\mathrm{o}$

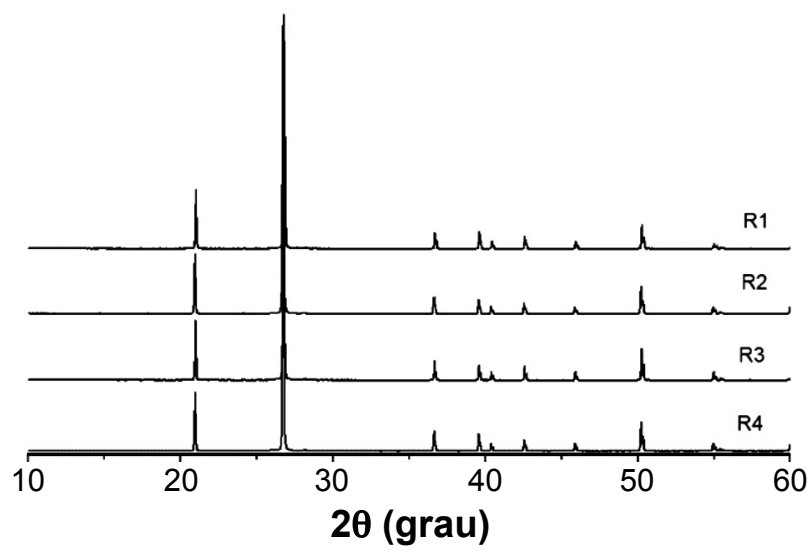

Figura 1: Difratogramas de raios X para os refratários R1, R2, R3 e R4 moídos.

[Figure 1: X-ray diffraction patterns for the ground refractories $R 1, R 2, R 3$ and $R 4$.
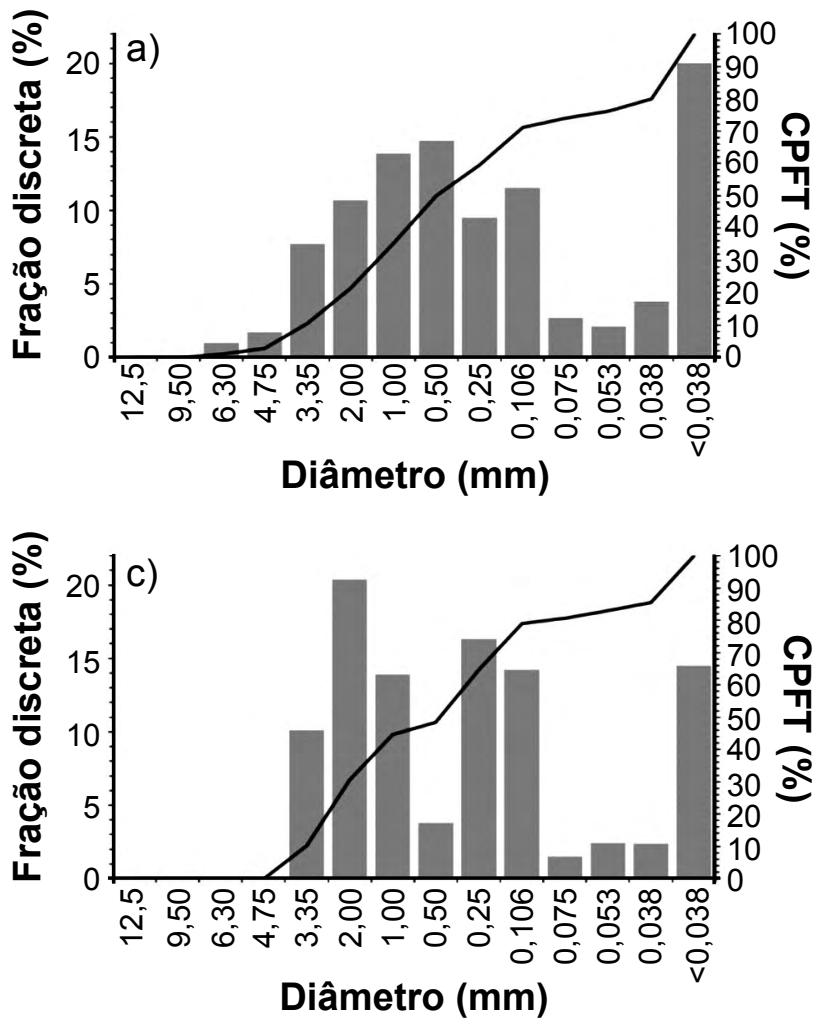

aquecimento, sendo que estas transformações envolvem variações dimensionais significativas que podem interferir no desempenho térmico do refratário. Os difratogramas de raios $\mathrm{X}$ dos quatro refratários empregados, denominados $\mathrm{R} 1, \mathrm{R} 2, \mathrm{R} 3$ e R4, confirmaram a presença da sílica na forma de quartzo, identificado conforme arquivo padrão ICSD $\mathrm{n}^{\circ}$ 46-1045, sem a presença de outras formas polimórficas (Fig. 1).

As quatro massas refratárias analisadas apresentaramse na forma de material particulado seco com distribuições granulométricas representadas na Fig. 2. Destes gráficos foi possível determinar o teor de finos, definido como o material com tamanho de partícula inferior a $0,038 \mathrm{~mm}$, o diâmetro médio de partícula $\left(\mathrm{D}_{50}\right)$ e o diâmetro máximo de partícula $\left(\mathrm{D}_{\mathrm{L}}\right.$, Tabela II). As massas refratárias R1 e R2 apresentaram características semelhantes, assim como o tamanho médio de partícula e formato da curva representativa de percentual discreto similares. Diferenciaram-se entre si pelo maior teor de finos presentes na massa refratária R1 (fração $<0,038 \mathrm{~mm}$ ). A massa refratária $\mathrm{R} 3$ foi a que apresentou o menor diâmetro máximo de partícula, enquanto a massa refratária R4 foi a que apresentou a maior dispersão de tamanho de partícula, sendo a que apresentou o maior diâmetro máximo de partícula $(>12,5 \mathrm{~mm})$.

O maior tamanho máximo de partícula, associado a um volume significativo de material fino pode ser correlacionado a problemas de segregação de materiais particulados no processo de adensamento por vibração,
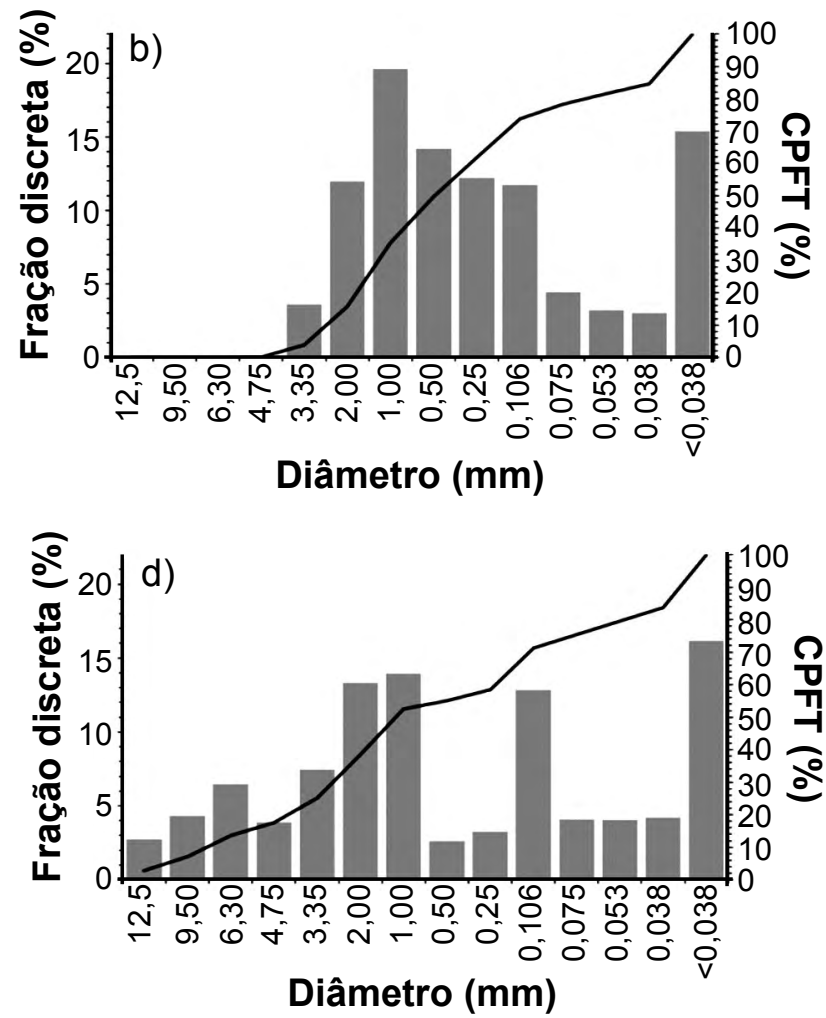

Figura 2: Curvas de distribuição de tamanho de partículas acumulada (CPFT) e discreta das massas refratárias secas utilizadas: a) R1; b) R2; c) R3; e d) R4.

[Figure 2: Accumulated (CPFT) and discrete particle size distribution curves of dry refractory masses: a) R1; b) R2; c) R3; and d) R4.] 
Tabela II - Parâmetros representativos da distribuição granulométrica para os quatro refratários estudados.

[Table II - Representative parameters of the granulometric distribution for the four refractories studied.]

\begin{tabular}{cccc}
\hline Refratário & $<0,038 \mathrm{~mm}$ & $\mathrm{D}_{50}(\mathrm{~mm})$ & $\mathrm{D}_{\mathrm{L}}(\mathrm{mm})$ \\
\hline $\mathrm{R} 1$ & $20,07 \%$ & 0,46 & 9,50 \\
R2 & $15,41 \%$ & 0,50 & 4,75 \\
R3 & $14,53 \%$ & 0,50 & 4,75 \\
R4 & $16,20 \%$ & 1,26 & $>12,50$ \\
\hline
\end{tabular}

entretanto a maior dispersão no tamanho de partícula pode resultar em incremento na eficiência de empacotamento [10]. Assim, além de levar em consideração a curva de distribuição de tamanho de partícula, deve-se avaliar as condições de compactação empregadas. Da mesma forma, a presença de maior quantidade de fração fina pode ser relacionada à possibilidade de formação de aglomerados que podem prejudicar o processo de preenchimento dos moldes comprometendo o adensamento dos materiais, dependendo da técnica de compactação adotada [10]. Essa relação entre a curva de distribuição de tamanho de partícula com a eficiência de empacotamento, associada à condição de adensamento, é destacada por diferentes pesquisadores $[11,12]$ que utilizaram como base os modelos de estudo de empacotamento e a determinação do coeficiente de distribuição q. Segundo Andreassen, o máximo adensamento é atingido quando o coeficiente de distribuição q apresenta valores entre 0,33 e 0,50 [4]. Resultados apresentados por Dinger e Funk, obtidos a partir de simulação numérica, mostram que a máxima densidade de empacotamento é alcançada quando o expoente q é igual a 0,37 [4, 11]. Estudos realizados posteriormente mostraram que o coeficiente de distribuição adequado para máxima densificação varia de acordo com a tecnologia de conformação sendo considerados adequados valores de q entre 0,19 e 0,21 para colagem por barbotina, enquanto para prensagem a seco os valores podem variar entre 0,33 e 0,5 [12]. Para as quatro massas refratárias estudadas, foi utilizado o modelo de Andreassen considerando os valores de porcentagem acumulada de partículas menores que um diâmetro específico $\mathrm{D}_{\mathrm{p}}$ (CPFT), assumindo como tamanho máximo de partícula o valor de $\mathrm{D}_{\mathrm{L}}$ determinado para cada material (Tabela II). Utilizou-se o modelo de Andreassen por assumir que não existe um diâmetro mínimo de partícula, o que significa assumir que esse valor é zero. Neste modelo a relação entre o CPFT e $\mathrm{D}_{\mathrm{p}}$ resulta em uma reta ao ser representado em um gráfico em escala log-log. Neste gráfico, a inclinação da curva define o valor do expoente q. Os valores do expoente para os quatro materiais estudados estão representados na Tabela III. Todos os valores foram dentro da faixa considerada adequada para maior densificação em materiais compactados a seco.

Além da distribuição granulométrica, deve-se considerar a morfologia das partículas empregadas sendo que a maior eficiência de empacotamento é obtida para materiais formados por partículas esféricas. Para os quatro materiais
Tabela III - Valores do expoente q determinados a partir do modelo de Andreassen para os quatro refratários estudados. [Table III - Values of the exponent $q$ determined from the Andreassen model for the four refractories studied.]

\begin{tabular}{cccc}
\hline R1 & R2 & R3 & R4 \\
\hline 0,32 & 0,39 & 0,40 & 0,30 \\
\hline
\end{tabular}

estudados, as frações de dimensões maiores apresentaram morfologia irregular com partículas de formato angular (Fig. 3). Assim, a eficiência de empacotamento deve ser influenciada pelo formato das partículas, resultando em um empacotamento menos eficiente. A presença desta fração grosseira é importante, pois garante a maior resistência ao choque térmico, propriedade fundamental para os materiais refratários. Estas partículas maiores também são responsáveis por garantir a transmissão da força de compactação para todo o volume da peça, garantindo maior uniformidade de adensamento [13]. Já a fração média tendeu a ser formada por partículas com menor rugosidade superficial e aparência esferoidal, o que pode ser associada à maior eficiência de acomodação de partícula em um processo de adensamento, especialmente para os materiais denominados R3 e R4 (Fig. 4). Por fim as frações finas apresentaram novamente tendência à morfologia acicular, independentemente do material analisado.

A avaliação do desempenho de adensamento dos materiais foi realizada através da determinação da densidade solta e densidade vibrada. No primeiro caso considera-se o efeito de preenchimento de um molde sem o auxílio de vibração ou outra ação que possa favorecer a acomodação de partículas. Já no caso da densidade vibrada considerase o efeito da compactação e vibração no aumento da densidade final. Os resultados foram apresentados também na forma de densidade relativa determinada com base na
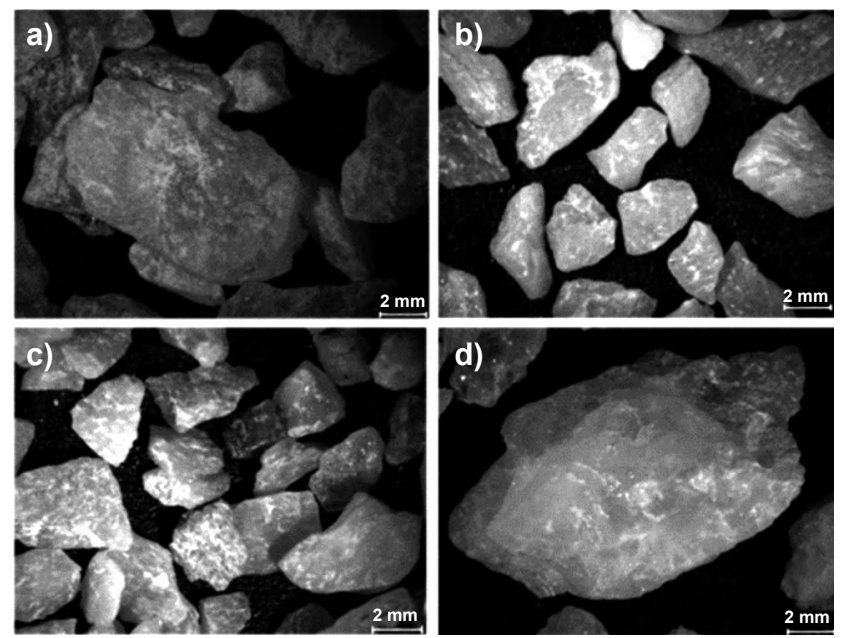

Figura 3: Micrografias obtidas por microscopia óptica da fração grossa das massas refratárias secas: a) R1; b) R2; c) R3; e d) R4. [Figure 3: Micrographs obtained by optical microscopy of the coarse fraction of the dry refractory masses: a) $R 1$; b) $R 2$; c) $R 3$; and d) R4.] 

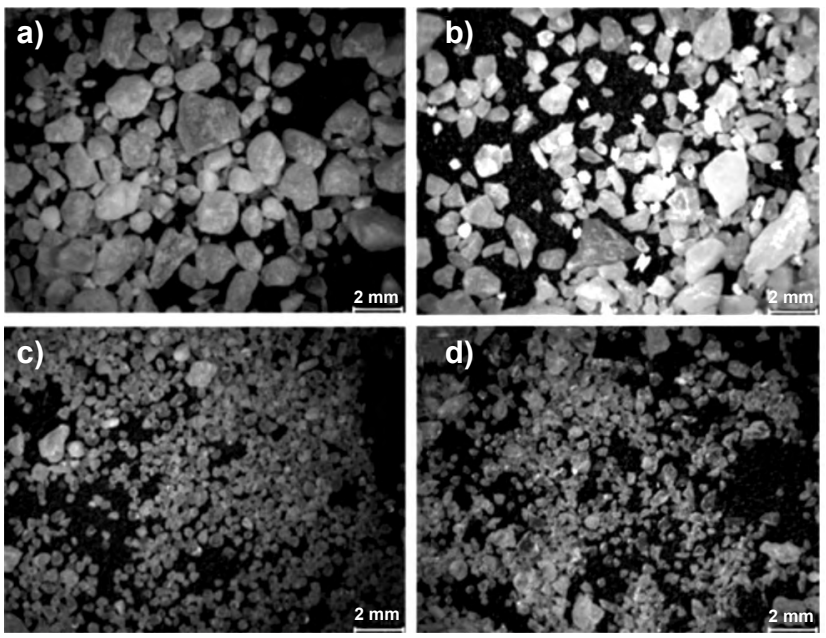

Figura 4: Micrografias obtidas por microscopia óptica da fração média das massas refratárias secas: a) R1; b) R2; c) R3; e d) R4.

[Figure 4: Micrographs obtained by optical microscopy of the mean fraction of the dry refractory masses: a) $R 1$; b) $R 2$; c) $R 3$; and d) R4.]

densidade picnométrica dos materiais estudados (Tabela IV). Quando avaliada a densidade solta, os valores foram bastante próximos, indicando comportamentos semelhantes para todos os materiais, onde a densidade máxima alcançada foi entre $60,96 \%$ e $62,28 \%$. Este efeito foi influenciado pela morfologia das partículas que foi semelhante para todos os materiais. A maior diferença foi observada quando avaliada a densidade vibrada para os quatro materiais. Ficou evidente o maior aumento da densidade média para o refratário R4, de 1,643 para $2,142 \mathrm{~kg} / \mathrm{m}^{3}$. Este resultado mostrou que para este material a ação mecânica favoreceu efetivamente o efeito de adensamento do material. Quando avaliada a densidade picnométrica dos quatro materiais, percebeu-se que todos apresentaram valores semelhantes e próximos ao valor da densidade da sílica na forma de quartzo que é $2,650 \mathrm{~g} / \mathrm{cm}^{3}$. $\mathrm{O}$ resultado deixou claro que o processo de adensamento manual, realizado industrialmente, tem efeito significativo e fundamental para o maior adensamento do material e consequentemente para o desempenho deste no que se refere à resistência à penetração de escória ou voláteis. $\mathrm{O}$ aumento da densidade por vibração pode chegar a $30 \%$ do valor da densidade solta, o que foi obtido para o refratário R4. Para os demais materiais o aumento da densidade variou entre $17,6 \%$ e 19,2\%. Esta diferença entre o refratário R4 e os demais pode ser explicada, em parte, pela maior diferença entre os valores mínimos e máximos de tamanho de partícula. Por outro lado, não foi identificada uma relação direta entre a densidade relativa atingida e o coeficiente de distribuição q. Este resultado permitiu afirmar que, para estes materiais, a consideração do expoente q definido no modelo de Andreassen como único critério de seleção de curva de distribuição de tamanho de partícula ideal para máxima densificação não é adequada, devendo ser considerados outros fatores como percentual de fração fina e diâmetro máximo de partículas.

Para avaliar o comportamento do material durante o processo de aquecimento tornou-se necessária a confecção de corpos de prova com resistência mecânica adequada ao manuseio dos mesmos. Para isto optou-se pela confecção de corpos de prova cilíndricos por prensagem uniaxial convencional. A sinterização foi realizada por aquecimento a $1400{ }^{\circ} \mathrm{C}$. A Fig. 5 apresenta de forma gráfica os valores de densidades solta, vibrada e compactada para os quatro materiais. Foi possível constatar que os valores das densidades vibrada e compactada foram bastante próximos, indicando que o processo de vibração garantiu um bom adensamento do material mesmo sem a utilização de força externa de compactação. Para os refratários R3 e R4 os valores de densidade compactada foram inferiores aos da densidade vibrada, mostrando para estes casos a importância do processo de vibração para acomodação das partículas no molde. Assim, o processo de adensamento mais eficiente deve contar com o efeito de vibração e pressão aplicados simultaneamente.

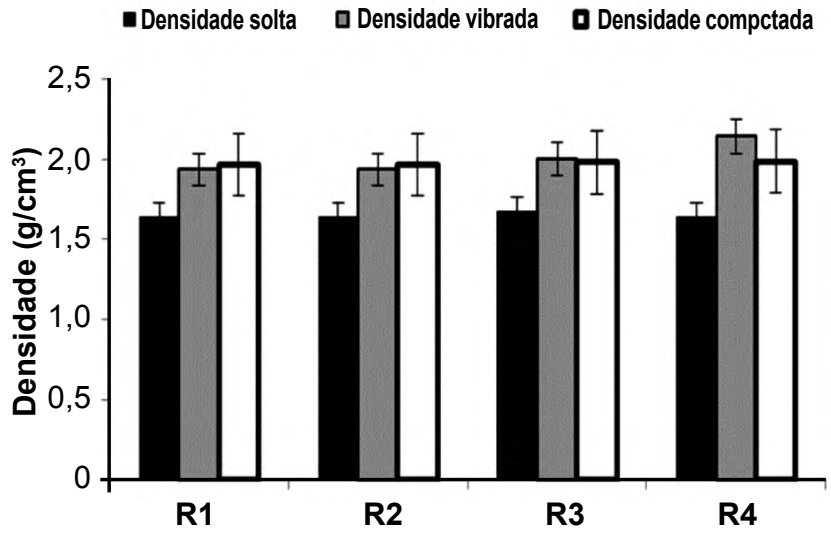

Figura 5: Comparação das densidades solta, vibrada e compactada. [Figure 5: Comparison of loose, vibrated and compacted densities.]

Tabela IV - Resultados de densidades picnométrica, solta, vibrada e relativa para as quatro massas refratárias estudadas. [Table IV - Results of pycnometric, loose, vibrated and relative densities for the four refractory masses studied.]

\begin{tabular}{cccccc}
\hline \multirow{2}{*}{ Refratário } & \multicolumn{3}{c}{ Densidade $\left(\mathrm{kg} / \mathrm{m}^{3}\right)$} & \multicolumn{2}{c}{ Densidade relativa (\%) } \\
& Picnométrica & Solta & Vibrada & Solta & Vibrada \\
\hline R1 & $2,6844 \pm 0,0004$ & $1,644 \pm 0,010$ & $1,94 \pm 0,10$ & 61,30 & 72,10 \\
R2 & $2,6977 \pm 0,0014$ & $1,644 \pm 0,007$ & $1,94 \pm 0,06$ & 60,96 & 71,75 \\
R3 & $2,6924 \pm 0,0008$ & $1,676 \pm 0,008$ & $2,00 \pm 0,12$ & 62,28 & 74,28 \\
R4 & $2,6785 \pm 0,0008$ & $1,643 \pm 0,001$ & $2,14 \pm 0,11$ & 61,36 & 80,00 \\
\hline
\end{tabular}


A Fig. 6 apresenta as medidas de porosidade aparente e absorção de água que, em conjunto com a densidade, correspondem às propriedades cerâmicas obtidas nos corpos de prova sinterizados. Foi evidente a redução da densidade dos materiais com o tratamento térmico a $1400{ }^{\circ} \mathrm{C}$. Esta densidade foi relacionada com os valores de absorção de água e porosidade, sendo que maiores valores de porosidade foram associados a menores massas específicas aparentes. Esta porosidade, que permanece elevada no material mesmo por aquecimento em temperaturas próximas a $1400{ }^{\circ} \mathrm{C}$, favorece o efeito de interação entre o metal fundido, os componentes volatilizados e o refratário. A maior porosidade favorece assim a penetração de voláteis que podem influenciar negativamente no desempenho e na vida útil do refratário. Estudos post mortem realizados em refratários siderúrgicos mostraram a influência da interação entre o metal fundido, a escória e os refratários e destacaram o efeito da porosidade na penetração de metais de baixa temperatura de ebulição, como é o caso do zinco [14]. A infiltração do vapor de zinco pode favorecer a condensação deste na forma de metal ou óxido em regiões interiores dos refratários, podendo causar danos ao refratário ou mesmo ao forno quando a condensação ocorrer próximo às bobinas. As interações entre o vapor de zinco e o refratário podem ocorrer tanto em refratários básicos como refratários não básicos [15].

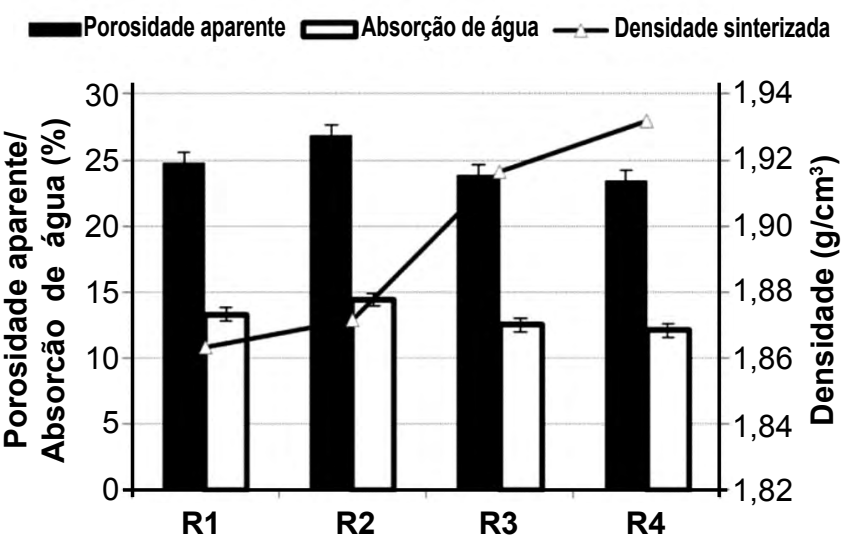

Figura 6: Medida da porosidade aparente, absorção de água e densidade sinterizada.

[Figure 6: Measurement of apparent porosity, water absorption and sintered density.]

A diferença na densidade aparente e porosidade dos refratários, submetidos a tratamento térmico, pode estar associada à combinação da densificação resultante da sinterização e à expansão resultante da formação de fase líquida. Para refratários de sílica a formação de fase líquida ocorre em função da interação entre a sílica e o óxido de boro. Esta fase líquida se forma em decorrência da presença de um eutético entre sílica e óxido de boro a $450{ }^{\circ} \mathrm{C}$ [16], sendo que o volume de fase líquida formada aumenta com o aumento do teor de boro presente e da temperatura de trabalho. A formação da fase líquida favorece o efeito de coesão entre partículas, o que pode explicar, em parte, o aumento da resistência ao manuseio dos corpos de prova submetidos ao tratamento térmico a $1400{ }^{\circ} \mathrm{C}$. O efeito da presença de fase líquida pode estar associado também à redução da porosidade aparente. A maior variação volumétrica associada à expansão térmica é relacionada às transformações de fase da sílica, presente inicialmente na forma de quartzo. A sílica cristalina existe em três estados diferentes: quartzo, tridimita e cristobalita. O quartzo é a forma estável na temperatura ambiente até $870{ }^{\circ} \mathrm{C}$, entre 870 e $1470{ }^{\circ} \mathrm{C}$ encontra-se a tridimita e entre 1470 e $1723{ }^{\circ} \mathrm{C}$ encontra-se a cristobalita [10]. Todas essas transformações ocorrem com mudança de volume importante, entretanto são transformações lentas e são identificadas em refratários de sílica submetidos a vários ciclos térmicos. Apesar da possibilidade de serem identificados fatores que favoreçam a densificação e fatores que podem resultar em expansão do material, é possível afirmar que a reduzida variação dimensional dos materiais (Fig. 7) foi associada principalmente à baixa temperatura de tratamento térmico utilizada para este tipo de material. Para os quatro materiais estudados foi identificado um efeito de expansão térmica inferior a $1,1 \%$.

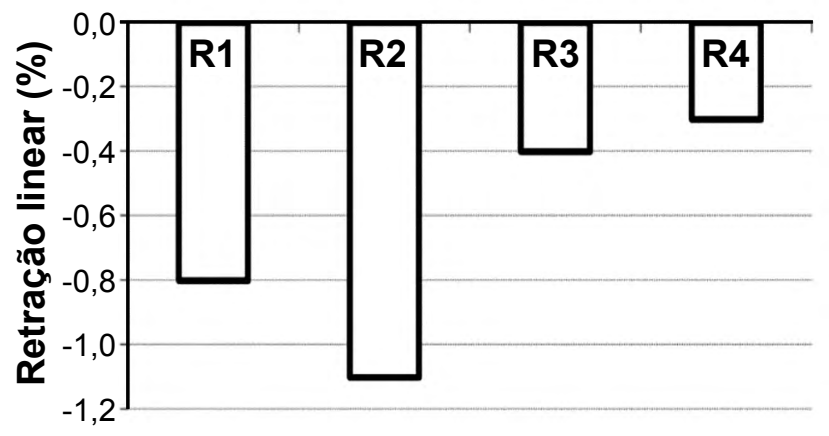

Figura 7: Medidas da retração linear (desvio padrão $=0,03$ ).

[Figure 7: Results of linear retraction (standard deviation $=0.03$ ).]

\section{CONCLUSÕES}

As massas de refratário secas estudadas, formadas pela combinação de sílica na forma de quartzo e óxido de boro, apresentaram curvas de distribuição de tamanho de partícula bastante distintas, com variação na concentração de finos $(14,53 \%$ a $20,07 \%)$ e no diâmetro máximo de partícula $(4,75$ a $12,50 \mathrm{~mm})$, sendo a massa $\mathrm{R} 1$ a mais fina e a massa R4 a mais grosseira. Apesar destas diferenças, todas apresentaram curvas de distribuição de tamanho de partícula compatíveis com materiais particulados adequados para atingir bom adensamento em processos de compactação. Todos os materiais foram formados por partículas com morfologia predominantemente angular que pode ser responsável pela menor eficiência de acomodação das partículas e menor densificação. O material R4, que teve como grande diferencial o maior diâmetro máximo de partícula, foi o que atingiu a maior densidade por vibração, entretanto, foi o que apresentou menor eficiência de compactação por prensagem e redução da densidade sinterizada. Todos os materiais, quando submetidos ao 
tratamento térmico a $1400{ }^{\circ} \mathrm{C}$, apresentaram efeito final de expansão com redução da densidade, apresentando porosidade aparente entre $23 \%$ e $27 \%$. Esta porosidade serve como porta de entrada para a penetração do vapor de zinco que é prejudicial ao desempenho do refratário. Porém a presença de porosidade é inevitável, pois favorece o processo de expansão sem a formação de microtrincas resultantes da variação volumétrica envolvida. Desta forma torna-se necessário buscar uma alternativa viável para evitar a penetração do vapor de zinco no revestimento. A massa R4 apresentou maior densidade vibrada e sinterizada, menor porosidade e menor retração linear, desta forma, esta massa seria indicada para minimizar penetração de vapores e escórias, sendo que a única restrição seria a maior influência do processo de compactação, que foi associada à sua granulometria ser mais dispersa.

\section{AGRADECIMENTOS}

Os autores agradecem à UDESC, à Capes e à FAPESC pelo apoio financeiro.

\section{REFERÊNCIAS}

[1] L.S. Cotta, C.G. Rodrigues, Exacta 7, 1 (2014) 185.

[2] G. Harris, Fund. Matér.-Primas 177 (2015) 52.
[3] E. Heinen, Fund. Matér.-Primas 177 (2015) 16.

[4] I.R. Olieira, A.R. Studart, R.G. Pileggi, V.C. Pandolfelli, Dispersão e empacotamento de partículas: princípios e aplicações em processamento cerâmico, Fazendo Arte Ed., S. Paulo (2000).

[5] Y.K. Kalpakli, Arch. Mater. Sci. Eng. 34, 2 (2008) 81.

[6] D.R. Dinger, J.E. Funk, Interceram 41, 2 (1992) 95.

[7] C.C. Hardt, "Alternativas de cargas para forno indução", http://foundrygate.com/, ac. 08/2018.

[8] M.T. Souza, F.R. Cesconeto, S. Arcaro, F.P. Raupp, A.P. Novaes de Oliveira, Cerâmica 60, 356 (2014) 569.

[9] Nat. Pollut. Invent., "Boron \& compounds fact sheet", Dep. Env. Herit., Austr. Gov. (2006).

[10] C.R. Cruz, "Refratários para siderurgia", Ass. Bras. Metais, S. Paulo (1987).

[11] R. Sarkar, Interceram Int. Ceram. Rev. 65, 3 (2016) 82.

[12] J. Fruhstorfer, C.G. Aneziris, J. Ceram. Sci. Tech. 5, 2 (2014) 155.

[13] P.C. Kapur, T. Indian Ceram. Soc. 33 (2014) 1.

[14] B.V. Almeida, E.S. Neves, S.N. Silva, F.V. Junior, Mater. Res. 20 (2017) 814.

[15] D. Gregurek, S. Redik, C. Wenzl, A. Spanring, in $7^{\text {th }}$ Int. Symp. High-Temp. Metal. Proc., Springer, Cham (2016) 149.

[16] M.S. Cilla, M.R. Morelli, Cerâmica 58, 345 (2012) 71. (Rec. 11/06/2018, Rev. 03/10/2018, 05/01/2019, Ac. 19/03/2019) 